\title{
Effects of emotional picture on movement trajectory: The role of meaning and the power of context
}

\author{
Wpływ obrazu emocjonalnego na tor ruchu: rola znaczenia i siły kontekstu
}

\begin{abstract}
Jose Luis Vilchez ${ }^{1,2}$
${ }^{1}$ Department for Management of Science and Technology Development, Ton Duc Thang University, Ho Chi Minh City, Vietnam ${ }^{2}$ Faculty of Applied Sciences, Ton Duc Thang University, Ho Chi Minh City, Vietnam
\end{abstract}

Neuropsychiatria i Neuropsychologia 2017; 12, 1: 1-11

Address for correspondence:

Ton Duc Thang University

Nguyen Huu Street 19, Tan Phong Ward, District 7

Ho Chi Minh City, Vietnam

e-mail: vilchez.tornero@tdt.edu.vn

\section{Abstract}

Aim of the study: The present study tests the effect of the attention to emotional content on movement trajectory. Methods: Pictures with positive and negative valence were presented on both sides of a simulated road in a driving-simulation tracking task for a series of two experiments for a total of 28 participants.

Results: Both the approach and withdrawal effects toward/from the position in which emotional cues appeared have been found on the participants' trajectory. In contrast to previous literature and common-sense hypotheses, these effects depended on the picture-presentation setting more than on their emotional valence. Some predictions in the literature pointed to finding approach movements for positive pictures and withdrawal behaviours for negative valences. In this sense, only negative pictures presented in close positions on the left-side of the road have been found to provoke approach tendencies.

Conclusions: The "emotional", right hemisphere processed picture presentations on the left side. Since it is impossible to select negative emotional pictures that do not have high emotional arousal, results point out to pictures arousal as the cause of the effects found. These findings are discussed under the perspectives of hemisphere laterality and models of motor control. The present study supports the MDRA model in its premise about how context can modify the meanings of attentional cues and, in turn, their impact on movement programming.

Key words: motor control, movement, emotion, attention, laterality.

\section{Introduction}

The relationship between attention and movement has been conventionally studied by using both exogenous and endogenous cues in discrete-trial tasks (e.g. Lee 1999). A number of models (see Vilchez 2013, for a review) that attempt to explain the effects found in the literature (veering-towards/away movements from the position where attentional cues were presented) have been generated. These models are founded on the premise of an overlap in the neural movement codification towards different stimuli (cf. Georgeopoulos 1995; 1990).

However, Vilchez and Tornay (2012) showed that the effect of attentional cues on trajectory movement is explained by their meaning. This meaning of cues has been proven to be also modulated by the presentation setting (e.g. Vilchez 2015). Therefore, the conjunction between the meaning per se of stimuli and the context in which these stimuli are presented is key for the influence of attention on movement, as Meaning-Dependent Response Activation (MDRA) model proposes (Vilchez 2013).

Whatever the motor codification toward cues might be (a veering-towards/away movement or an attractive/repulsive effect), in every given task with more than one stimulus (target and distractor/s), the inhibition of the competing, automatic-elicited responses to distractor/s is required (Tipper et al. 1992). To this aim, the cognitive system has an inhibitory mechanism that, in normal conditions, rules out the outputs to distractors, in order to achieve subjects' goals (e.g. Welsh and Elliott 2004). This mechanism has been proposed to be efficient but not entirely effective (e.g. Vilchez and Tornay 2012). Continuous tasks, such as the tracking task (see Wickens and Hollands, 2000 for a review), are sensitive at assessing, upon movement, the 
lack of inhibitory effectiveness of our cognitive system.

With regards to the effect of emotional meanings on movement, Chen and Bargh (1999) showed that words with emotional valence, such as love or hate, had a differential effect on the action of pulling or pushing a lever. In this sense, participants' reaction times were faster when responding to positive words in pulling the lever toward themselves. On the other hand, participants were faster when pushing the lever away from themselves when the words had emotional, negative valence. Therefore, the results showed that the direction of the effect is in accordance with logical behavioural responses. That is to say, positive emotions facilitate approach behaviour, and negative emotions generate avoidance tendencies.

Accordingly, differential activation of the left frontal areas (for positive emotions) and of the right frontal areas (for negative content) can be found in the literature (e.g. Lee et al. 2004; Tomarken et al. 1992). In this sense, it has been proposed that approach-related emotions are associated with left hemisphere activation, while withdrawal-related emotions have been linked to right hemisphere activity (Davidson 1998). This is an important point to take into account in the present work because emotional pictures
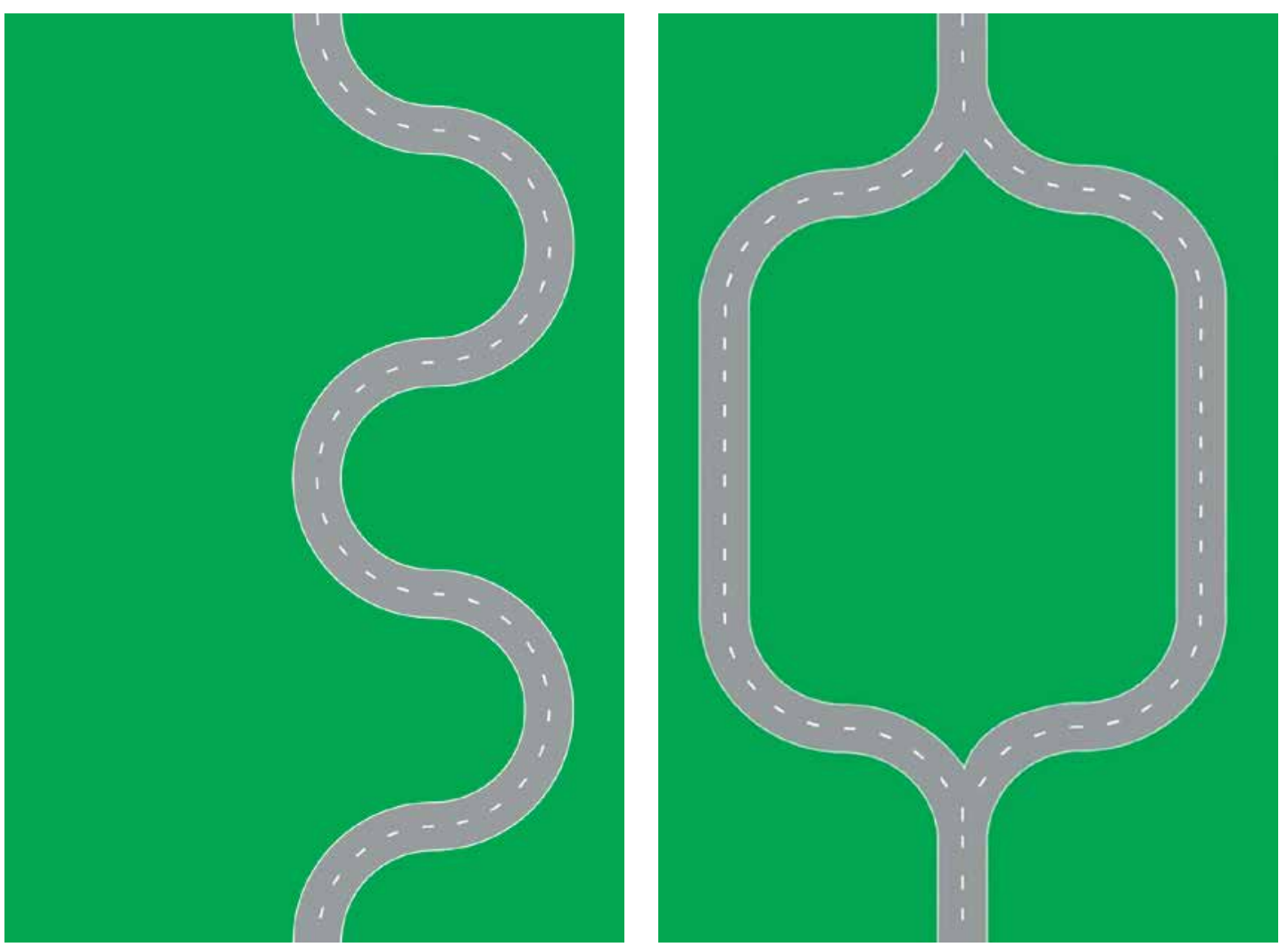

Fig. 1. On the left, example of non-experimental background. On the right, example of experimental background

were presented on both sides of a simulated road in a tracking task. Pictures were symmetrically presented from the centre of the road. Therefore, stimuli presented in the right visual hemifield are processed by the left hemisphere and vice versa.

The aim of the present study is to clarify the influence of the emotional meaning of attentional cues on a continuous movement trajectory. In this case, the meaning was manipulated by using experimental pictures with positive and negatives valence. The hypotheses about the kind of effect of the emotional valence on participants' trajectory are based on the limited literature that points to approach-to-positive/ withdraw-from-negative behaviours (e.g. Chen and Bargh 1999).

\section{General method}

\section{Experimental methods used}

Overview. Experiment 1 and 2 follow the paradigm of Vilchez (2015) to measure the influence of the attention-to-stimuli on movement.

\section{Stimuli}

A 60-pixel-wide, grey road was presented on 800-pixel-wide, green backgrounds (see Figure 1 as reference). The simulated road was limited 

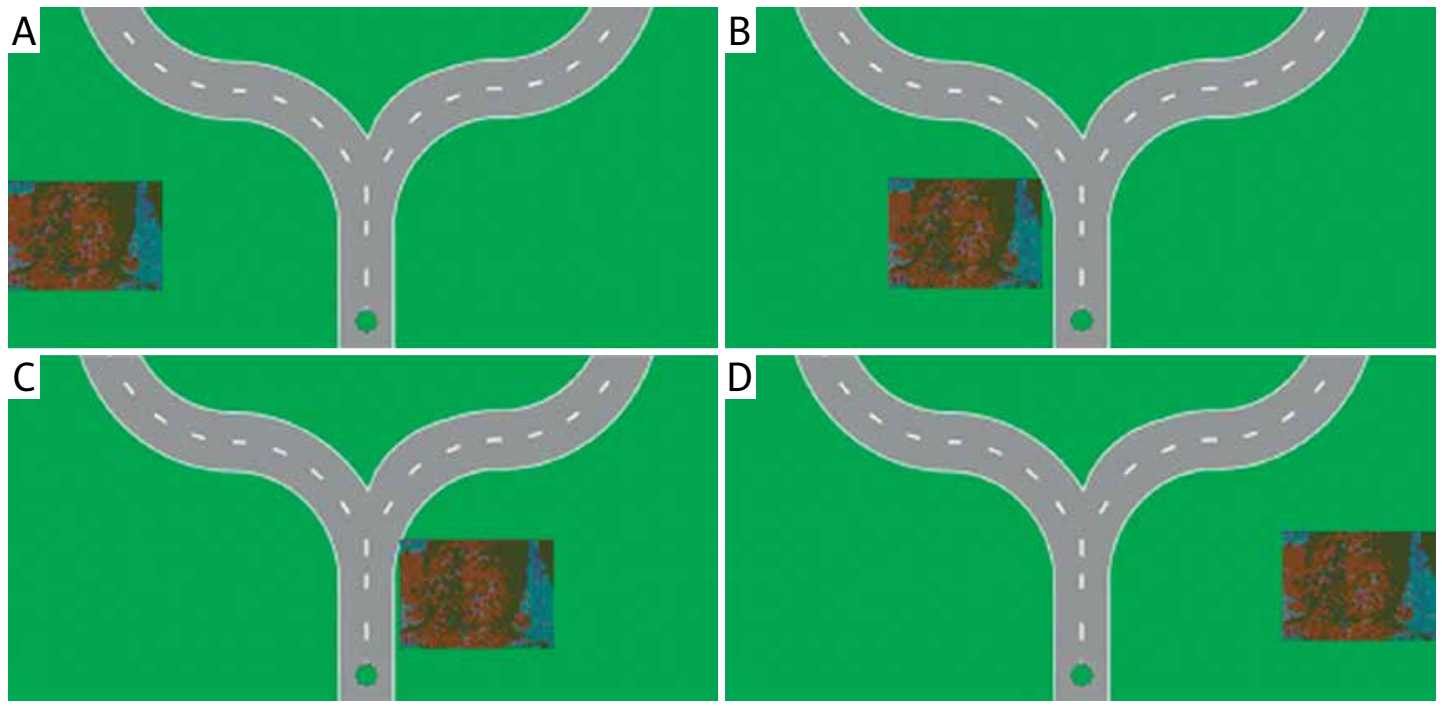

Fig. 2. Example of each position where positive or negative pictures were presented. From left to right and up to down: (A) left-far position; (B) left-close position; (C) right-close position; and (D) right-far position

by two continuous, white lines and divided into two by a three-pixel-wide, discontinuous, white line. Two kinds of backgrounds were presented: non-experimental and experimental backgrounds (see Figure 1). Non-experimental backgrounds were created with several routes where the road turned right and left (see Vilchez 2015 for a description of the methodology in detail).

Participants controlled a green circle 22 pixels in diameter, with a black circumference, and a central dot (see Figure 2 as a reference). Emotional pictures were overlapped on both sides of the road in the experimental backgrounds. These stimuli were selected from the International Affective Picture System (IAPS; Lang et al. 2005) on the basis of the Spanish normative population in valence and arousal (Vila et al. 2001). Negative cues were eight pictures (database numbers 3000, 3071, 3170, 3350, 3550, 6312, 9040, and 9410) with unpleasant content (e.g. illness, mutilations, or natural disasters), and a mean valence of 1.78 and 7.49 in arousal. Positive cues were another eight pictures (database numbers 2040, 2091, 2340, 4599, 5260, 5830, 8540, and 8600) with pleasant content (e.g. babies, landscapes, or circumstances that symbolise goal achievement) and a mean valence of 7.77 and 4.41 for arousal. Valence and arousal values range from 1 to 9; 1 being negative content and low arousal, and 9 being positive content and high arousal. The same set of pictures was used along with more stimuli as a mood-induction procedure in previous studies; being always successful at both individual and group level (e.g. Pacheco-Unguetti et al. 2014).

\section{Instruments and tracking task}

An HP Intel ${ }^{\circledR}$ Core $^{\mathrm{TM}} 2$ T5500 (1.66Ghz@ $1.66 \mathrm{GHz}, 0.99$ RAM GB and Mobile Intel ${ }^{\circledR}$ 945 Express Chipset Family screen adapter), with a $43.9-\mathrm{cm}$ diameter screen, was used to present stimuli and record participants 'movement trajectories. Participants controlled the green circle stimulus with a Momo Logitech steering wheel. The steering wheel movements modified the position of the centre of the green circle on the $x$-axis. Its position on the $y$-axis was fixed at a specific location (see Figure 2 as a reference). Backgrounds ran across the screen, giving a feeling of movement.

The aim of the task was to track the centre of the simulated road with the green circle during approximately $20 \mathrm{~min}$. The road was designed by using a randomised sequence of both experimental and non-experimental backgrounds. In the experimental background, an emotional stimulus (a positive or negative picture) appeared on each side of the road depending on the experimental condition. The blocks of experiments consisted of four randomised trials without repeating any condition. Between blocks, the sequence of appearance was also randomised, and every block was balanced. The total number of blocks was eight.

\section{Procedure}

Once participants were seated approximately $1.2 \mathrm{~m}$ from the computer screen, and after having filled in the informed consent form, they were given the instructions of the task. The instructions specified the possible appearance of distractors (emotional pictures) during the performance of 
the task. Participants were informed that they were free to take the route they wanted to in the Y-junction that appears in experimental backgrounds (see Figure 1 as a reference). Once the task finished, participants were given their reward for their collaboration. They were also asked to report if anything unusual regarding their performance was noticed while conducting the task.

\section{Statistics}

The total number of data rows (or registered frames) was exactly 17,601 per participant. Data were filtered by experimental conditions and different measure stages, previous or subsequent to the emotional picture presentation. In the first measurement stage (see Figure 3 as reference), the space before the picture presentation (pre-cue stage or A frames) was coded as the general-movement control condition. During the second measurement stage, the space where the picture was being presented (cue-appearance stage or B frames), the codification depended on experimental conditions. In the third measurement stage, the space where the picture disappeared (post-cue stage or $\mathrm{C}$ frames), the codification depended on the experimental condition of the previous second stage.

The error was calculated by subtracting, frame by frame, the position of the centre of the road from the $x$-position of the green circle. Since the effect has a differential influence in time, a repeated measures ANOVA was conducted on every experimental frame belonging to cue-appearance (B frames) and post-cue (C frames) stages. Pre-cue general movement control stage (A frames) was not included in the analysis because in this stage the different experimental conditions were not presented.

On the other hand, the two possible routes to take in the Y-junction in experimental back- grounds were also analysed. To this end, the number of occasions on which the participants took a certain route for every experimental condition was assessed.

\section{Experiment 1}

Based on previous works (Chen and Bargh 1999), it is predicted that positive pictures will provoke an approach/attraction effect on the movement trajectory towards the location where cues are presented. On the other hand, negative pictures are thought to trigger withdrawal/ repulsive tendencies. However, based on the MDRA model (Vilchez 2013), this effect could be modified by the context of presentation of pictures, restructuring even the emotional meaning of the cue and, in turn, its effect on movement.

\section{Method}

\section{Participants}

Thirteen undergraduate, right-handed students from the University of Magallanes, Chile, aged 18-25-years-old $(M=19.2, S D=2.32$ seven females), participated in this first experiment. With a similar amount of participants, statistical analyses showed sufficient statistical power and representativeness (Vilchez 2015). All participants reported normal or corrected-to-normal vision and hearing, and were naïve to the purpose of the experiment. They obtained course credits for their participation.

\section{Experimental methods used}

Emotional pictures appeared in experimental backgrounds, approximately 123 pixels before the Y-junction. Namely, the picture appeared on the left or right-hand side of the road, only in close positions for Experiment 1 (see Figure 2

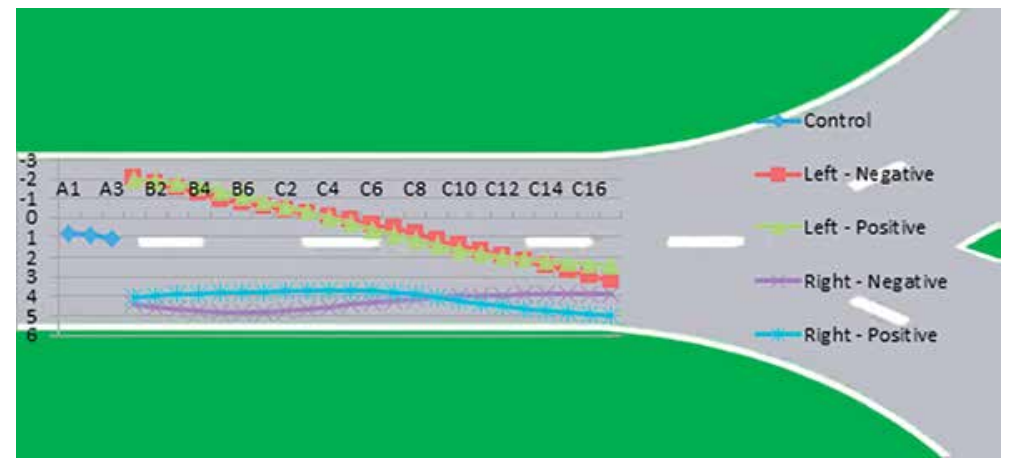

Negative values indicate deviation to the left, and positive values indicate deviation to the right

Fig. 3. Average deviations in pixels (y-axis) in every experimental condition throughout the measurement process (A, B, and C frames, $x$-axis) in Experiment 1 
Table 1. Tests of statistical significance for cue-position, cue-valence, and their interaction throughout the measurement process (from cue-appearance) in Experiment 1

\begin{tabular}{|c|c|c|c|c|c|c|c|c|c|c|}
\hline \multicolumn{2}{|c|}{ Codification } & \multicolumn{3}{|c|}{ Cue-position effect } & \multicolumn{3}{|c|}{ Cue-valence effect } & \multicolumn{3}{|c|}{ Interaction effect } \\
\hline Frame & Presentation course & $F(1,12)$ & MSE & $p$ & $F(1,12)$ & MSE & $p$ & $F(1,12)$ & MSE & $p$ \\
\hline B1 & Cue-appearance & $=17.52$ & $=29.06$ & $<.01^{*}$ & $=0.01$ & $=51.04$ & $>.25$ & $=0.03$ & $=18.86$ & $>.25$ \\
\hline B2 & Cue-appearance & $=17.77$ & $=27.48$ & $<.01^{*}$ & $=0.04$ & $=50.04$ & $>.25$ & $=0.05$ & $=18.17$ & $>.25$ \\
\hline B3 & Cue-appearance & $=17.42$ & $=26.38$ & $<.01^{*}$ & $=0.07$ & $=48.01$ & $>.25$ & $=0.07$ & $=17.38$ & $>.25$ \\
\hline B4 & Cue-appearance & $=16.96$ & $=25.26$ & $<.01^{\star}$ & $=0.11$ & $=45.86$ & $>.25$ & $=0.07$ & $=16.57$ & $>.25$ \\
\hline B5 & Cue-appearance & $=16.55$ & $=23.71$ & $<.01^{\star}$ & $=0.14$ & $=43.88$ & $>.25$ & $=0.07$ & $=15.94$ & $>.25$ \\
\hline B6 & Cue-appearance & $=16.41$ & $=21.85$ & $<.01^{\star}$ & $=0.15$ & $=41.51$ & $>.25$ & $=0.09$ & $=14.77$ & $>.25$ \\
\hline $\mathrm{C} 1$ & Post Cue & $=15.89$ & $=20.56$ & $<.01^{*}$ & $=0.15$ & $=38.86$ & $>.25$ & $=0.13$ & $=13.72$ & $>.25$ \\
\hline $\mathrm{C} 2$ & Post Cue & $=15.49$ & $=19.13$ & $<.01^{*}$ & $=0.12$ & $=36.67$ & $>.25$ & $=0.17$ & $=12.82$ & $>.25$ \\
\hline C3 & Post Cue & $=14.72$ & $=17.59$ & $<.01^{\star}$ & $=0.10$ & $=34.59$ & $>.25$ & $=0.23$ & $=11.72$ & $>.25$ \\
\hline C4 & Post Cue & $=13.61$ & $=16.41$ & $<.01^{*}$ & $=0.06$ & $=32.15$ & $>.25$ & $=0.28$ & $=10.68$ & $>.25$ \\
\hline C5 & Post Cue & $=12.69$ & $=15.15$ & $<.01^{\star}$ & $=0.03$ & $=29.71$ & $>.25$ & $=0.30$ & $=9.76$ & $>.25$ \\
\hline C6 & Post Cue & $=11.87$ & $=13.97$ & $<.01^{\star}$ & $=0.01$ & $=27.52$ & $>.25$ & $=0.26$ & $=8.91$ & $>.25$ \\
\hline C7 & Post Cue & $=11.28$ & $=12.67$ & $<.01^{\star}$ & $=0.01$ & $=25.50$ & $>.25$ & $=0.21$ & $=8.21$ & $>.25$ \\
\hline C8 & Post Cue & $=10.83$ & $=11.21$ & $<.01^{*}$ & $=0.01$ & $=23.25$ & $>.25$ & $=0.15$ & $=7.69$ & $>.25$ \\
\hline C9 & Post Cue & $=10.44$ & $=9.83$ & $<.01^{*}$ & $=0.01$ & $=21.27$ & $>.25$ & $=0.04$ & $=7.09$ & $>.25$ \\
\hline $\mathrm{C} 10$ & Post Cue & $=10.29$ & $=8.56$ & $<.01^{*}$ & $=0.03$ & $=19.53$ & $>.25$ & $=0.01$ & $=6.90$ & $>.25$ \\
\hline $\mathrm{C} 11$ & Post Cue & $=10.27$ & $=7.57$ & $<.01^{*}$ & $=0.05$ & $=17.87$ & $>.25$ & $=0.03$ & $=6.74$ & $>.25$ \\
\hline $\mathrm{C} 12$ & Post Cue & $=9.91$ & $=9.99$ & $<.01^{\star}$ & $=0.08$ & $=16.80$ & $>.25$ & $=0.13$ & $=6.82$ & $>.25$ \\
\hline $\mathrm{C} 13$ & Post Cue & $=9.21$ & $=6.71$ & $<.01^{*}$ & $=0.10$ & $=15.80$ & $>.25$ & $=0.35$ & $=6.99$ & $>.25$ \\
\hline C14 & Post Cue & $=8.33$ & $=6.51$ & $<.01^{*}$ & $=0.09$ & $=15.01$ & $>.25$ & $=0.64$ & $=6.94$ & $>.25$ \\
\hline C15 & Post Cue & $=7.21$ & $=6.61$ & $<.02^{*}$ & $=0.08$ & $=14.50$ & $>.25$ & $=0.88$ & $=7.32$ & $>.25$ \\
\hline $\mathrm{C} 16$ & Post Cue & $=5.90$ & $=7.04$ & $<.03^{*}$ & $=0.06$ & $=13.90$ & $>.25$ & $=1.11$ & $=7.94$ & $>.25$ \\
\hline $\mathrm{C} 17$ & Post Cue & $=4.48$ & $=7.90$ & $=.06$ & $=0.02$ & $=13.78$ & $>.25$ & $=1.36$ & $=8.72$ & $>.25$ \\
\hline
\end{tabular}

${ }^{\star}$ Frames with significant effect

as a reference), 70 pixels from the centre of the road (cue-position variable), during six registered frames (each frame with an average duration of $60 \mathrm{~ms})$. Figure 2 has been degraded due to copyright not to offend readers. The emotional picture could have a negative or positive valence (cue-valence variable). Therefore, the design was $2 \times 2$ (cue-position $\times$ cue-valence) with the four experimental conditions of: (a) left-positive, (b) left-negative, (c) right-positive, and (d) right-negative.

\section{Results}

\section{Trajectory}

A significant effect was found for cue-position from frame $\mathrm{B} 1, F(1,12)=17.56$,
MSE $=29.06, p<.01, \eta_{p}^{2}=.59$, to frame C16, $F(1,12)=5.9, M S E=7.04, p<.03$, $\eta_{p}{ }^{2}=.33$ (see Table 1 ). With regards to cue-valence, there was no significant effect from frame B1 to frame $\mathrm{C} 17, F(1,12)=.01, M S E=51.04$, $p=.93$, and $F(1,12)=.02, M S E=13.7$, $p=.87$, respectively. No interaction effect was found from frame B1, $F(1,12)=.03, M S E=$ $18.86, p=.86$, to frame $\mathrm{C} 17$ either, $F(1,12)=$ $1.36, M S E=8.72, p=.27$.

The results show a positionally-attractive, exogenous effect to the location in which cues were presented (cue-position variable, see Figure 3). That is to say, when emotional picture, independently of their emotional valence, were presented on the left-side of the road, average deviation increased to the left - taking more 
negative values. On the other hand, when pictures appeared on the right-side of the road, the average deviation rose to the right - taking more positives values.

\section{Route taken}

The count of the number of times every participant chose a specific option was weighted to the total number of possible choices. Data were subjected to a repeated measures ANOVA $2 \times 2$ (cue-position $X$ cue-valence), focusing only on one option, since the options were symmetrical; i.e. taking the right route is equivalent to not taking the left route in a specific trial. No significant effect in this measure was found for cue-position, $F(1,12)=0.46, M S E=.1$, $p=.5$, cue-valence, $F(1,12)=0.01, M S E=.1$, $p=.91$, or their interaction, $F(1,12)=0.1$, $M S E=.1, p=.93$

\section{Discussion}

These results show an overall exogenous, attractive effect for cue-position. Emotional pictures significantly attract the movement toward the same side of the road as they are presented from frame B1 to C16 (see Table 1 and Figure 3). These findings replicate prior results found in the literature dealing with non-emotional significance (e.g. Vilchez 2015). However, regarding the direction of the effect, data are in contrast to aforementioned postulates that predicted an approach tendency for positive content and a withdrawal behaviour for negative valence (e.g. Chen and Bargh 1999; Davidson 1992). As the second premise of the MDRA model (Vilchez 2013) states, the meaning of cues is decisive in provoking the kind of effect on movement. In this particular case, for both meanings (positive and negative valences), participants veer to the same side of the road on which the emotional cues were presented. Participants are attracted by the pictures and they move closer to the location in which those pictures are presented, independently of their emotional valence.

In this sense, no significant differences have been shown for left and right hemifields, and therefore, not for the differential, hemispherical processing either, in contrast to previous works (e.g. Lee et al. 2004; Tomarken et al. 1992). This lack of differential effect for each hemisphere is suggested to be due to the slight distance between the centre of the road and the position of the apparition of cues (either on the left or on the right).

\section{Experiment 2}

Regarding the point of laterality, previous literature has shown that the right hemisphere is also dominant in mediating attention in distal space, in contrast to the prevalence of the left hemisphere in proximity (Heilman et al. 1995). In this sense, to the best of my knowledge, there is no literature that supports that this differential proximal/distal modulation of the hemispheres works the same with emotional content. Taking into account the laterality perspectives (Lee et al. 2004; Tomarken et al. 1992), the hypothesis for Experiment 2 is that there will be differential effects for different locations along the perpendicular $x$-axis to the centre of the road ( $y$-axis). To this aim, distances to the centre of the road were manipulated in order to check the effect of proximity/distance. In line with Heilman et al. (1995), the MDRA model (Vilchez 2013) proposes that the change of meaning, caused by the change of the cue-presentation context, will change the effect on the movement trajectory. This new meaning will provoke the same emotional stimuli (pictures) used in Experiment 1 to have a different effect on movement than the one previously found. Furthermore, the manipulation of the cue-position and cue-valence remained the same for Experiment 2.

\section{Method}

\section{Participants}

Fifteen undergraduate, right-handed students from the University of Magallanes aged $18 / 22$-years-old $(M=19.83, S D=1.44$, eight females) participated in this experiment. All participants reported normal or corrected-to-normal vision and hearing, and were naïve to the purpose of the experiment. They obtained course credits for their participation.

\section{Experimental methods used}

Stimuli, apparatus, task, and data analyses were identical to those of the previous experiment, except for the introduction of a third variable: cue-proximity. In this experiment, emotional pictures could be presented into a closer to or farther away position from the center of the road (see Figure 2). Therefore, the design was 2 (cue-position) $\times 2$ (cue-valence) $\times 2$ (cue-proximity)

\section{Results}

\section{Trajectory}

A repeated measures ANOVA 2 (cue-position) $\times 2$ (cue-valence) $\times 2$ (cue-proximity) was con- 
ducted on B and C frames, as in Experiment 1. There was a main effect for cue-valence for frames B1 to B3, $F(1,14)=5.3, M S E=45.6$, $p<.04, \eta_{p}^{2}=.27$, and $F(1,14)=4.91$, $M S E=43.75, p<.05, \eta_{p}^{2}=.26$, respectively. For cue-position, there was no significant effect from frame B1, $F(1,14)=1.67, M S E=$ $54.07, p=.22$, to frame $\mathrm{C} 17, F(1,14)=.83$, $M S E=44.43, p=.38$. No significant effect was found for cue-proximity either, B1, $F(1,14)$ $=2.45, M S E=56.02, p=.14$, and frame $\mathrm{C} 17, F(1,14)=1.16, M S E=69.77, p=.3$ (see Table 2).

Figure 4 shows the evolution of cue-valence effect throughout the measurement stages. Because cue-position had a significant main effect in Experiment 1, cue-position conditions have been added for a better visualisation of the differences between both effects.

In contrast to previous results, only emotional pictures presented on the left-side of the road had an effect on movement. In this sense, negative contents presented on the left side attract the participants' movement to the same left side of the road, while positive ones significantly provoke participants to veer towards the right side of the road.

With regard to primary interactions between the three variables, there were no significant effects for cue-position $X$ cue-valence, cue-position $\times$ cue-proximity, or cue-valence $\times$ cue-proximity, from frame B1 to $\mathrm{C} 17$. For the secondary

Table 2. Tests of statistical significance for cue-position, cue-proximity, and cue-proximity throughout the measurement process (from cue-appearance) in Experiment 2

\begin{tabular}{|c|c|c|c|c|c|c|c|c|c|c|}
\hline \multicolumn{2}{|c|}{ Codification } & \multicolumn{3}{|c|}{ Cue-position effect } & \multicolumn{3}{|c|}{ Cue-valence effect } & \multicolumn{3}{|c|}{ Cue-proximity effect } \\
\hline Frame & Presentation course & $F(1,14)$ & MSE & $p$ & $F(1,14)$ & MSE & $p$ & $F(1,14)$ & MSE & $p$ \\
\hline B1 & Cue-appearance & $=1.67$ & $=54.07$ & $=.22$ & $=5.3$ & $=45.60$ & $<.04^{*}$ & $=2.45$ & $=56.02$ & $=.14$ \\
\hline B2 & Cue-appearance & $=1.75$ & $=54.46$ & $=.21$ & $=5.14$ & $=44.18$ & $<.04^{*}$ & $=2.34$ & $=55.07$ & $=.15$ \\
\hline B3 & Cue-appearance & $=1.85$ & $=53.80$ & $=.19$ & $=4.91$ & $=43.75$ & $<.05^{*}$ & $=2.17$ & $=54.95$ & $=.16$ \\
\hline B4 & Cue-appearance & $=1.93$ & $=53.02$ & $=.19$ & $=4.56$ & $=43.72$ & $=.05$ & $=2.02$ & $=55.6$ & $=.18$ \\
\hline B5 & Cue-appearance & $=2.05$ & $=52.01$ & $=.17$ & $=4.16$ & $=43.66$ & $=.06$ & $=1.86$ & $=57.25$ & $=.19$ \\
\hline B6 & Cue-appearance & $=2.15$ & $=50.32$ & $=.16$ & $=3.77$ & $=43.73$ & $=.07$ & $=1.68$ & $=58.51$ & $=.22$ \\
\hline $\mathrm{C} 1$ & Post Cue & $=2.17$ & $=48.71$ & $=.16$ & $=3.42$ & $=43.35$ & $=.23$ & $=1.58$ & $=59.56$ & $=.23$ \\
\hline$C 2$ & Post Cue & $=2.18$ & $=47.24$ & $=.17$ & $=2.96$ & $=42.56$ & $=.11$ & $=1.46$ & $=60.78$ & $=.25$ \\
\hline C3 & Post Cue & $=1.98$ & $=45.59$ & $=.18$ & $=2.55$ & $=41.93$ & $=.13$ & $=1.36$ & $=63.55$ & $>.25$ \\
\hline C4 & Post Cue & $=1.82$ & $=44.32$ & $=.20$ & $=2.19$ & $=41.65$ & $=.16$ & $=1.29$ & $=65.45$ & $>.25$ \\
\hline C5 & Post Cue & $=1.70$ & $=42.92$ & $=.21$ & $=1.84$ & $=41.86$ & $=.2$ & $=1.24$ & $=67.75$ & $>.25$ \\
\hline C6 & Post Cue & $=1.59$ & $=41.82$ & $=.23$ & $=1.51$ & $=42.87$ & $=.24$ & $=1.21$ & $=68.94$ & $>.25$ \\
\hline$C 7$ & Post Cue & $=1.52$ & $=40.59$ & $=.24$ & $=1.25$ & $=45.22$ & $>.25$ & $=1.21$ & $=69.76$ & $>.25$ \\
\hline C8 & Post Cue & $=1.46$ & $=39.16$ & $=.25$ & $=1.05$ & $=47.24$ & $>.25$ & $=1.17$ & $=71.08$ & $>.25$ \\
\hline C9 & Post Cue & $=1.39$ & $=38.25$ & $>.25$ & $=0.89$ & $=49.96$ & $>.25$ & $=1.17$ & $=72.18$ & $>.25$ \\
\hline $\mathrm{C} 10$ & Post Cue & $=1.34$ & $=37.56$ & $>.25$ & $=0.77$ & $=52.57$ & $>.25$ & $=1.18$ & $=73.10$ & $>.25$ \\
\hline C11 & Post Cue & $=1.30$ & $=37.59$ & $>.25$ & $=0.67$ & $=55.33$ & $>.25$ & $=1.17$ & $=73.27$ & $>.25$ \\
\hline C12 & Post Cue & $=1.18$ & $=37.23$ & $>.25$ & $=0.57$ & $=58.68$ & $>.25$ & $=1.19$ & $=72.76$ & $>.25$ \\
\hline C13 & Post Cue & $=1.06$ & $=37.63$ & $>.25$ & $=0.56$ & $=60.12$ & $>.25$ & $=1.16$ & $=71.65$ & $>.25$ \\
\hline C14 & Post Cue & $=0.97$ & $=38.92$ & $>.25$ & $=0.57$ & $=62.32$ & $>.25$ & $=1.14$ & $=70.54$ & $>.25$ \\
\hline C15 & Post Cue & $=0.90$ & $=41.11$ & $>.25$ & $=0.54$ & $=65.64$ & $>.25$ & $=1.15$ & $=70.45$ & $>.25$ \\
\hline C16 & Post Cue & $=0.83$ & $=44.43$ & $>.25$ & $=0.54$ & $=69.01$ & $>.25$ & $=1.16$ & $=69.77$ & $>.25$ \\
\hline C17 & Post Cue & $=0.83$ & $=44.43$ & $>.25$ & $=0.54$ & $=69.01$ & $>.25$ & $=1.16$ & $=69.77$ & $>.25$ \\
\hline
\end{tabular}

${ }^{\star}$ Frames with significant effect 


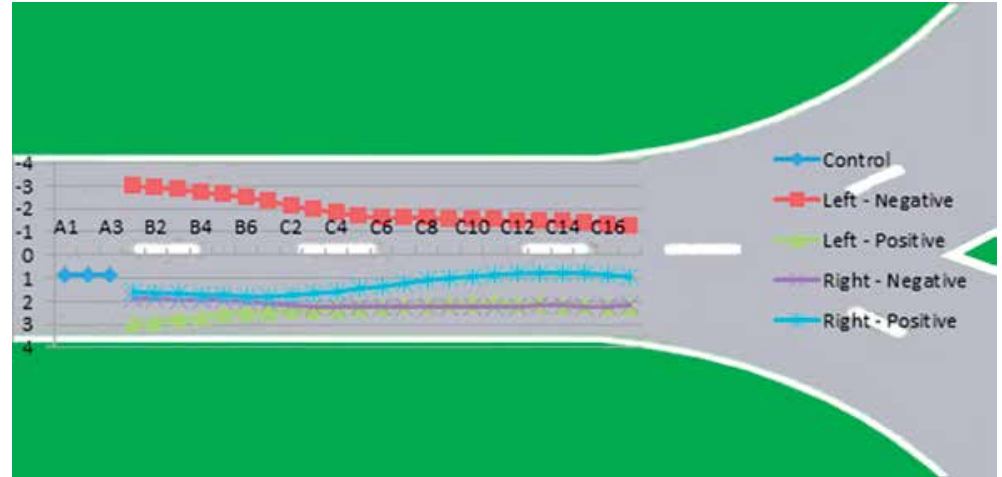

Negative values indicate deviation to the left, and positive values indicate deviation to the right

Fig. 4. Average deviations in pixels (y-axis) in every experimental condition throughout the measurement process (A, B, and $C$ frames, $x$-axis) in Experiment 2

interaction, a significant effect was found for cue-position $\times$ cue-valence $\times$ cue-proximity interaction from frame B1 to B3, $F(1,14)=$ 6.67, MSE $=49.1, p<.03, \eta_{p}^{2}=.32$, and $F(1,14)=5.12, M S E=51.4, p<.05, \eta_{p}^{2}=.27$ (see Table 3). Planned comparisons were carried out to clarify this interaction. Results showed that only left-negative-close/far comparison was significant for B1 frame, $F(1,14)=4.85$, $M S E=39.1, p<.05$.

Figure 5 shows the direction of the effect, focusing on the emotional pictures that were presented in left side of the road, where there was the only effect of this interaction. The sense of the effect is that only when emotional pictures had a negative valence and were presented on a close position to the centre of the road, they attracted participants' movement towards the left side of the road. For all other positions, valences, and distances, participants gave a meaning to the cues that provoked them to take a "protection" position on the right-side of the road.

\section{Route taken}

A repeated measures ANOVA 2 (cue-position) $\times 2$ (cue-valence) $\times 2$ (cue-proximity) analysis was carried out over the count of weighted options made by participants. The results show that there were no significant effects for cue-position, $F(1,14)=0.01, M S E=14.55, p=.94$, cue-valence, $F(1,14)=29, M S E=11.49, p=.16$, or cue-proximity, $F(1,14)=1.18, M S E=5.85$, $p=.2$. Regarding primary interaction, none of them had a significant effect; cue-position $X$ cue-valence, $F(1,14)=0.62, M S E=31.45$, $p=.44$, cue-position $\times$ cue-proximity, $F(1,14)$ $=.42, M S E=8.39, p=.63$, and cue-valence $\times$ cue-proximity, $F(1,14)=0.26, M S E=8.38$, $p=.62$. Finally, no significant effect, $F(1,14)=$
4.3, MSE $=5.85, p=.06$, was found for the secondary interaction cue-position $\times$ cue-valence $x$ cue-proximity either.

\section{Discussion}

As in previous works (e.g. Vilchez 2015), the change of the presentation setting provoked the cancellation of the previous exogenous, positional-attractive effects found. The cue-position effect is neutralised by the effect of the change of meaning for the same cues in different presentation positions. As a main effect, cue-valence is not understood the same by participants when pictures were presented in the left side of the road, compared to when pictures were presented in the right side (see Figure 4). On the right side of the road, both positive and negative valences provoked an attractive/approach effect to the same right side. Nevertheless, on the left side, negative pictures provoked attraction/approach behaviour while positive ones triggered the opposite repulsive/withdrawal movements.

The interaction between the three variables (cue-position, cue-valence, and cue-proximity) was significant. Planned comparisons pointed out that the distance at which cues were presented modulates the effect of the cue-valence (only for presentations on the left side of the road). That is to say, the emotional meaning of pictures can be changed depending on where such content is presented and perceived. On the left side of the road, negative content attracts participants' movement only when this content is presented in closer positions to the centre of the road (see Figure 5). This same negative content, being perceived in faraway positions on the same side (left), provokes a "protection" stand. This stand is close to the centre of the right lane and indicates a qualitative, different 
Table 3. Tests of statistical significance for cue-position, cue-proximity, and cue-proximity throughout the measurement process (from cue-appearance) in Experiment 2

\begin{tabular}{|c|c|c|c|c|}
\hline \multicolumn{2}{|c|}{ Codification } & \multicolumn{3}{|c|}{ Cue-position-valence-proximity interaction } \\
\hline Frame & Presentation course & $F(1,14)$ & MSE & $p$ \\
\hline B1 & Cue-appearance & $=6,67$ & $=49.10$ & $<.03^{*}$ \\
\hline B2 & Cue-appearance & $=5.89$ & $=50.05$ & $<.03^{*}$ \\
\hline B3 & Cue-appearance & $=5.12$ & $=51.40$ & $<.05^{\star}$ \\
\hline B4 & Cue-appearance & $=4.45$ & $=53.28$ & $=.05$ \\
\hline B5 & Cue-appearance & $=3.88$ & $=55.43$ & $=.07$ \\
\hline B6 & Cue-appearance & $=3.38$ & $=59.14$ & $=.09$ \\
\hline $\mathrm{C} 1$ & Post Cue & $=3.00$ & $=61.93$ & $=.10$ \\
\hline C2 & Post Cue & $=2.64$ & $=63.62$ & $=.13$ \\
\hline C3 & Post Cue & $=2.41$ & $=65.75$ & $=.14$ \\
\hline C4 & Post Cue & $=2.18$ & $=67.93$ & $=.16$ \\
\hline C5 & Post Cue & $=1.96$ & $=69.32$ & $=.18$ \\
\hline C6 & Post Cue & $=1.75$ & $=71.50$ & $=.21$ \\
\hline C7 & Post Cue & $=1.58$ & $=72.52$ & $=.23$ \\
\hline C8 & Post Cue & $=1.43$ & $=73.94$ & $=.25$ \\
\hline C9 & Post Cue & $=1.32$ & $=74.74$ & $>.25$ \\
\hline $\mathrm{C} 10$ & Post Cue & $=1.25$ & $=75.60$ & $>.25$ \\
\hline $\mathrm{C} 11$ & Post Cue & $=1.17$ & $=76.32$ & $>.25$ \\
\hline $\mathrm{C} 12$ & Post Cue & $=1.12$ & $=77.49$ & $>.25$ \\
\hline $\mathrm{C} 13$ & Post Cue & $=1.06$ & $=78.93$ & $>.25$ \\
\hline C14 & Post Cue & $=1.00$ & $=80.36$ & $>.25$ \\
\hline C15 & Post Cue & $=0.97$ & $=81.49$ & $>.25$ \\
\hline C16 & Post Cue & $=0.97$ & $=81.79$ & $>.25$ \\
\hline $\mathrm{C} 17$ & Post Cue & $=0.95$ & $=82.81$ & $>.25$ \\
\hline
\end{tabular}

${ }^{*}$ Frames with significant effect

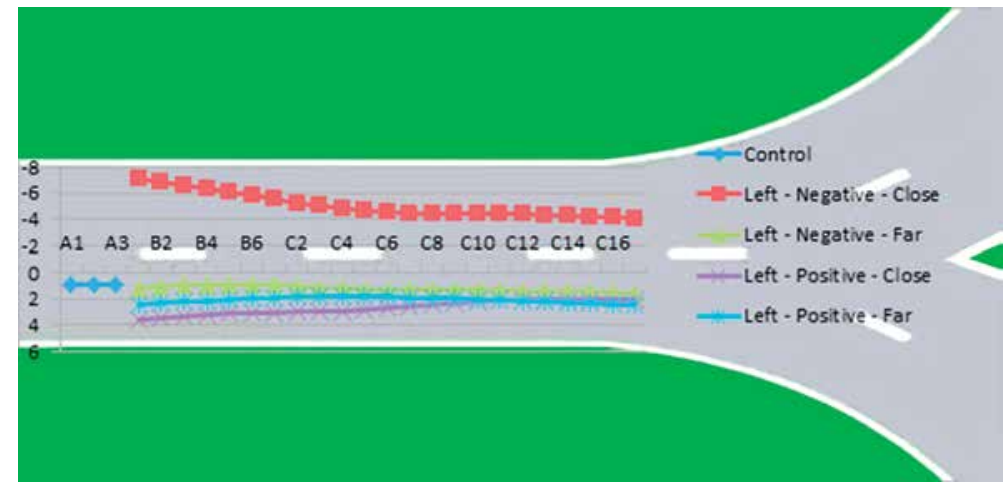

Negative values indicate deviation to the left, and positive values indicate deviation to the right

Fig. 5. Average deviations in pixels (y-axis) in all experimental condition just for cues presented on the left side of the road throughout the measurement process (A, B, and C frames, $\mathrm{x}$-axis) in Experiment 2 
effect. The results are in contrast to the predictions that pointed out the prevalence of the left hemisphere for attention to proximity and dominance of the right hemisphere for distal space (Heilman et al. 1995).

This effect, although significantly it lasts for only $180 \mathrm{~ms}$ (three frames $\times 60 \mathrm{~ms}$; see Table 3 ), is robust and continues determining the movement almost until the Y-junction (see Figure 5). Finally, the different arousal of negative (mean arousal of 7.49) and positive pictures (mean arousal of 4.41) could cause the differential effect of negative/positive content for cues presented in the left side of the road. In this sense, it is impossible to ensure that the negative and positive arousal were kept equal because the negative emotions are matched with high arousal and positive emotions are matched with low arousal. Future research will manipulate extreme arousals to test their effects on movement.

\section{Conclusions}

The results back previous findings (e.g. Chen and Bargh 1999), or even common sense, in pointing out effects of emotional content on movement. However, the direction of those predictions is not supported. In the literature, the so-called Behavioural Approach System (BAS, Gray 1994; 1972) or Behavioural Activation System (Fowles 1987; 1980) is suggested to be activated by incentive cues and to be responsible for approach tendencies and positive affect (Fowles 2001; Gray 1994). Neuroimaging and electroencephalography studies have also indicated that approach tendencies are related to higher activation in left prefrontal areas, which suggests that the underpinning, neural system for approaching is located in that hemisphere (see Harmon-Jones and Allen 1997 for a review). In contrast, in Experiment 1, no differences between negative and positive valences were found. Both valences attracted participants' trajectory movement to the position in which emotional pictures were presented.

On the other hand, the so-called Behavioural Inhibitory System (BIS, Gray 1972; 1994) is believed to generate withdrawal behaviour and anxiety. BIS is also related to a higher activation of the right prefrontal cortex (Davidson $e t$ al. 1990). However, in Experiment 1, no differences between presenting cues on the left/right visual hemifield were found. Presenting cues on the right of a foveal fixation (i.e. the centre of the road) makes the left hemisphere process the information presented in that side, and vice versa (Robertson and Lamb 1988). Nevertheless, results show that for both emotional valences participants veered toward the left for stimuli presented in the left side of the road, and to the right when cues were presented in the right side (see Figure 3).

Following the assumptions of the proximity/ distance differential modulation of the left/right hemisphere (Heilman et al. 1995), the found effect of the distance of the pictures from the centre of the road (cue-proximity) cannot be explained. In Experiment 2, negative content, presented in close positions on the left-side of the road, provoked an attraction/approach tendency to the left (see Figure 5). On the other hand, that negative content, in this same left side of the road but presented in a faraway position, provoked a repulsion/withdrawal effect on movement. If the right hemisphere was the hemisphere behind withdrawal behaviours (Davidson et al. 1990), the processing of this hemisphere of pictures presented on the left-side should trigger a withdrawal tendency in any case. This repulsion/withdrawal behaviour should be equal for all negative cues presented in the left-side, independently of the distance in which they appear. Further works using electroencephalography or neuroimaging will clarify the point of which hemisphere is activated in this tracking task and by what kind of emotional dimension (e.g. arousal vs. valence).

From the MDRA model's (Vilchez 2013) point of view, the results are clear. In the experimental setting in which emotional pictures can be properly perceived in close positions to the road (Experiment 1), their emotional meaning makes participants move closer to the location in which these cues have been presented, independently of their emotional valence (see Figure 3). On the other hand, when the context of stimuli presentation changes, the meaning of emotional pictures changes as well, modulating the effect previously found in Experiment 1. In this case, for Experiment 2, only negative pictures located in close position are sufficiently meaningful to provoke a veering-towards effect to their presentation location, causing a different effect in contrast to all other conditions.

Generally speaking, the meanings of emotional pictures were not evaluated by participants as "incentive" or "stressful" (Gray 1972; 1994) but as "interesting" (maybe provoked by their arousal). In this sense, it has been demonstrated that all pictures attracted participants' movement in Experiment 1, and only negative pictures presented on the left in close positions in Experiment 2. The change of 
cue-presentation setting provoked a change in the effect of the same emotional pictures from Experiment 1 to 2 . These results support the MDRA model in premise 2 (Vilchez 2013; p. 173): "Dependence on the kind of codification (such as attractive [approach behaviour] or repulsive [withdrawal tendency]) according to the meaning the stimulus has or the individual provides to it - not the stimulus saliency per se or its shared characteristic with other stimuli in the visual scene".

\section{References}

1. Chen M, Bargh JA. Nonconscious approach and avoidance behavioral consequences of the automatic evaluation effect. Pers Soc Psychol Rev Bull 1999; 25: 215-224.

2. Davidson RJ. Emotion and affective style: Hemispheric substrates. Psychol Sci 1992; 3: 39-43.

3. Davidson RJ. Affective style and affective disorders: Perspectives from affective neuroscience. Cogn Emot 1998; 12: 307-330.

4. Davidson RJ, Ekman P, Saron CD, et al. Approachwithdrawal and cerebral asymmetry: Emotional expression and brain physiology I. J Pers Soc Psychol 1990; 58: 330-341.

5. Fowles DC. Biological variables in psychopathology: A psychobiological perspective. In: Comprehensive handbook of psychopathology ( $3^{\text {rd }}$ ed.). Adams HE, Sutker PB (eds.). Plenum Press, New York 2001.

6. Fowles DC. Application of a behavioral theory of motivation to the concepts of anxiety and impulsivity. J Res Pers 1987; 21: 417-435.

7. Fowles DC. The three-arousal model: Implications of Gray's two-factor learning theory for heart rate, electrodermal activity, and psychopathy. Psychophysiology 1980; 17: 87-104.

8. Georgeopoulos AP. Current issues in directional motor control. Trends Neurosci 1995; 18: 506-510.

9. Georgeopoulos AP. Neurophysiology of reaching. In: Attention and performance XIII. Jeannerod M (ed.). Lawrence Erlbaum Associates Inc, Hillsdale 1990.

10. Gray JA. Personality dimensions and emotion systems. In: The nature of emotion: Fundamental. Ekman P, Davidson RJ (eds.). Oxford University Press, New York 1994.

11. Gray JA. The psychophysiological basis of introversion-extraversion: A modification of Eysenck's theory. In: Nebylitsyn VD, Gray JA (eds.). The biological bases of individual behaviour. Academic Press, New York 1972.

12. Heilman KM, Chatterjee A, Doty LC. Hemispheric asymmetries of near-far spatial attention. Neuropsychol 1995; 9: 58-61.

13. Lang PJ, Bradley MM, Cuthbert BN. International Affective Picture System (IAPS): Affective ratings of pictures and instruction manual (Tech. Report A-6). University of Florida, Center for Research in Psychophysiology, Gainesville 2005.

14. Lee D. Effects of exogenous and endogenous attention on visually guided hand Movements. Cogn Brain Res 1999; 8: 143-156.

15. Lee GP, Meador KJ, Loring DW, et al. Neural substrates of emotion as revealed by functional magnetic resonance imaging. Cogn Behav Neurol 2004; 17: 9-17.
16. Pacheco-Unguetti AP, Acosta A, Lupiáñez J. Recognizing the bank robber and spotting the difference: Emotional state and global vs. local attentional set. Span J Psychol 2014; 17: 1-12.

17. Robertson L, Lamb MR. The role of perceptual reference frames in visual field asymmetries. Neuropsychologica 1988; 26: 145-152.

18. Tipper SP, Lortie C, Baylis GC. Selective reaching: Evidence for action-centered attention. J Exp Psychol Hum Percept Perform 1992; 18: 891-905.

19. Tomarken A, Davidson RJ, Wheeler RE, et al. Individual differences in anterior brain asymmetry and fundamental dimensions of emotion. J Pers Soc Psychol 1992; 62: 676-687.

20. Vila J, Sánchez M, Ramírez I, et al. El Sistema Internacional de Imágenes Afectivas (IAPS): Adaptación Española (Part 2) [The International Affective Picture System (IAPS): Spanish adaptation]. Rev Psicol Gen Apl 2001; 54 : 635-657.

21. Vilchez JL. Effects of mental footnotes on the trajectory movement in a driving simulation task. J Motor Behav 2015; 47: 211-225.

22. Vilchez JL. The locus of Stimuli Meaning in the Influence of Attention on Movement: Meaning-Dependent Activation Model. J Mind Behav 2013; 34: 165-176.

23. Vilchez JL, Tornay FJ. Irrelevant stimuli produce a path deviation in a driving-simulation task. Cogn Syst Res 2012; 17-18: 81-89.

24. Welsh TN, Elliott D. Movement trajectories in the presence of a distracting stimulus: Evidence for a response activation model of selective reaching. Q J Exp Psychol 2004; 57A: 1031-1057.

25. Wickens CD, Hollands JG. Engineering psychology and human performance. Prentice Hall, Upper Saddle River 2000. 